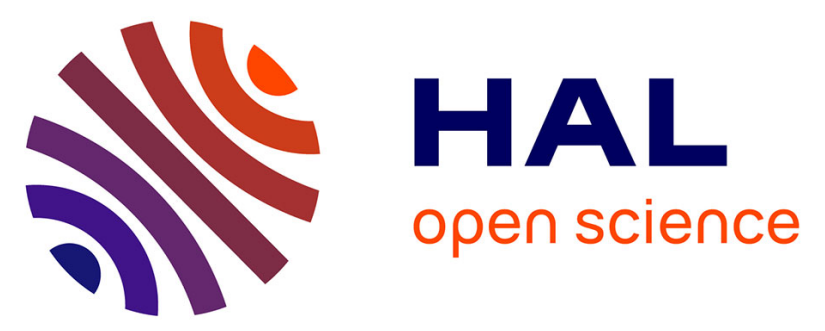

\title{
Molecular Recognition by Chalcogen Bond: Selective Chargetransfer Crystal Formation of Dimethylnaphthalene with Selenadiazolotetracyanonaphthoquinodimethane
} Yusuke Ishigaki, Kota Asai, Henri-Pierre Jacquot de Rouville, Takuya Shimajiri, Valérie Heitz, Hiroshi Fujii-Shinomiya, Takanori Suzuki

\section{To cite this version:}

Yusuke Ishigaki, Kota Asai, Henri-Pierre Jacquot de Rouville, Takuya Shimajiri, Valérie Heitz, et al.. Molecular Recognition by Chalcogen Bond: Selective Chargetransfer Crystal Formation of Dimethylnaphthalene with Selenadiazolotetracyanonaphthoquinodimethane. European Journal of Organic Chemistry, In press, 10.1002/ejoc.202001554 . hal-03114533

\section{HAL Id: hal-03114533 \\ https://hal.science/hal-03114533}

Submitted on 19 Jan 2021

HAL is a multi-disciplinary open access archive for the deposit and dissemination of scientific research documents, whether they are published or not. The documents may come from teaching and research institutions in France or abroad, or from public or private research centers.
L'archive ouverte pluridisciplinaire HAL, est destinée au dépôt et à la diffusion de documents scientifiques de niveau recherche, publiés ou non, émanant des établissements d'enseignement et de recherche français ou étrangers, des laboratoires publics ou privés. 


\title{
Molecular Recognition by Chalcogen Bond: Selective Charge- transfer Crystal Formation of Dimethylnaphthalene with Selenadiazolotetracyanonaphthoquinodimethane
}

\author{
Yusuke Ishigaki, ${ }^{[a]}$ Kota Asai, ${ }^{[a]}$ Henri-Pierre Jacquot de Rouville, ${ }^{[b]}$ Takuya Shimajiri, ${ }^{[a]}$ Valérie Heitz, ${ }^{[b]}$ \\ Hiroshi Fujii-Shinomiya, ${ }^{[\mathrm{c}, \mathrm{d}]}$ and Takanori Suzuki ${ }^{*[a]}$
}

In memory of François Diederich and Tsutomu Miyashi

\begin{abstract}
The title nonplanar electron acceptor (1) fused with a selenadiazole ring selectively forms a crystalline charge-transfer complex (CT crystal) with 2,6-dimethylnaphthalene (2,6-DMN). On the other hand, the sulfur analogue (2) has less recognition ability and forms CT crystals with both 2,6- and 2,7-DMN. X-ray analyses of 1,2 , and their CT crystals revealed that the Se $\bullet \bullet N$ chalcogen bond $(\mathrm{ChB})$ in $\mathbf{1}$ is strong enough to determine the crystal packing with the formation of a cavity suitable for 2,6-DMN. On the contrary, ChB through $S \bullet \bullet N$ contact in 2 competes with other weak interactions such as a $\mathrm{C}-\mathrm{H} \bullet \bullet \mathrm{N}$ hydrogen bond. The stronger $\mathrm{ChB}$ involving $\mathrm{Se}$ is the key for $\mathbf{1}$ to separate 2,6-DMN (>97 wt\%) from a complex isomer mixture containing ca. 10 wt\% each of 2,6and 2,7-DMN by a simple, efficient and straightforward mixingfiltration-heating process.
\end{abstract}

\section{Introduction}

Directional short contacts are of primary importance in stabilizing supramolecular systems. Indeed, hydrogen bonds are the most prevalent stabilizing interaction in biological architectures due to their directionality and relative strength in comparison to other weak interactions. However, protein structures can also be stabilized by directional short contacts between a divalent sulfur and an oxygen atom. ${ }^{[1]}$ More generally, these short contacts have been conceptualized as the interaction between an electrophilic chalcogen atom (E) and electron donor atoms (D) acting as a Lewis base. ${ }^{[2]}$ This stabilizing interaction (R-E $\bullet \bullet D$, where $R$ is an electron-withdrawing group) was reported in the solid state in the late 1960 's $\mathrm{s}^{[3]}$ but has gained a renewed interest over the last decade. Nowadays, it is referred to as the chalcogen bond $(\mathrm{ChB}) \cdot{ }^{[4]}$ The directionality of the ChB was explained by the existence of at least one $\sigma$-hole on the $E$ atom, which defines a positive electrostatic potential region in the direction opposite of the R-E bond. ${ }^{[5]}$ Thus, the $E$ atom acts as a Lewis acid that can be bound by a Lewis base through

\footnotetext{
[a] Dr. Y. Ishigaki, K. Asai, T. Shimajiri, Prof. Dr. T. Suzuki, Department of Chemistry, Faculty of Science Hokkaido University, Sapporo 060-0810 (Japan) E-mail: tak@sci.hokudai.ac.jp

[b] Dr. H.- P. Jacquot de Rouville, Prof. Dr. V. Heitz, Institut de Chimie de Strasbourg, CNRS UMR 7177, Université de Strasbourg, 4, rue Blaise Pascal, 67000 Strasbourg (France)

[c] Dr. H. Fujii-Shinomiya, Department of Chemistry, Faculty of Science Tohoku University, Sendai 980-8578 (Japan)

[d] On leave from Mitsubishi Oil Company, Co. Ltd. Supporting information for this article is available on the WWW at http://dx.doi.org/10.1002/****
}

Formula<smiles>N#CC(C#N)=c1c2ccccc2c(=C(C#N)C#N)c2nsnc12</smiles>

1: $E=S e$

2: $E=S$<smiles></smiles>

9: $\mathrm{E}=\mathrm{Se}$

10: $E=S$<smiles></smiles>

3: $\mathrm{E}=\mathrm{Se}$

4: $E=S$

5: $E=O$<smiles>Cc1ccc2cc(C)ccc2c1</smiles><smiles>Cc1ccc2ccc(C)cc2c1</smiles>

2,6-DMN

formation of eutectic mixture<smiles></smiles>

6: $E=E^{\prime}=S e$

7: $E=S e, E^{\prime}=S$

8: $E=E^{\prime}=S$
$\mathrm{n}(\mathrm{D}) \rightarrow \sigma^{*}(\mathrm{E}-\mathrm{R})$ electron donation. Interestingly, $\mathrm{E}$ atoms can present two $\sigma$-holes, thus allowing the interaction of two donor atoms simultaneously. The stability of the $\mathrm{ChB}$ is influenced by the nature of the $\mathrm{E}$ atom $(\mathrm{Te}>\mathrm{Se}>\mathrm{S}>>\mathrm{O})$, the nature of the electron-deficient R-group, the R-E $\bullet \bullet D$ angle (close to linear) and the Lewis basicity of $D^{[6]}$ A better understanding of these factors has led to application of the ChB in several fields of chemistry, such as supramolecular chemistry ${ }^{[7]}$ and catalysis. ${ }^{[8]}$ Even if the ChB is usually characterized by looking at the sum of the van der Waals (vdW) radii in the solid state, this highly directional interaction has scarcely been used in crystal engineering of organic compounds. ${ }^{[9]}$

Crystal engineering takes advantage of intermolecular interactions in the context of crystal packing to rationalize the design of new solids with desired physical and chemical properties. ${ }^{[10]}$ The crystal is described as the predictable assembly of molecules into networks of desired geometries, i.e., a supermolecule. ${ }^{[11]}$ Consequently, the molecular arrangement in the crystal relies on the nature of the interacting functional groups, also called supramolecular synthons, between molecules in the crystal. These supramolecular synthons allow a retrosynthetic approach by the straightforward determination of node connectivity in the crystals. Two major features of supramolecular synthons can be identified: i) their chemical nature and ii) their relative geometry. Therefore, the use of $\mathrm{ChB}$ synthons in crystal engineering is promising due to their high directionality. The $[\mathrm{E} \bullet \bullet \bullet N C]$ motif is a supramolecular synthon of choice since it is chemically robust. ${ }^{[12]}$ We previously used this supramolecular synthon in tetracyanoquinodimethane (TCNQ)-type compounds fused with 1,2,5-chalcogenadiazole(s) (3 - 8, Formula). ${ }^{[13]}$ Interestingly, the linearly-extended molecular networks formed by bis(thiadiazolo)-TCNQ (8) in the 


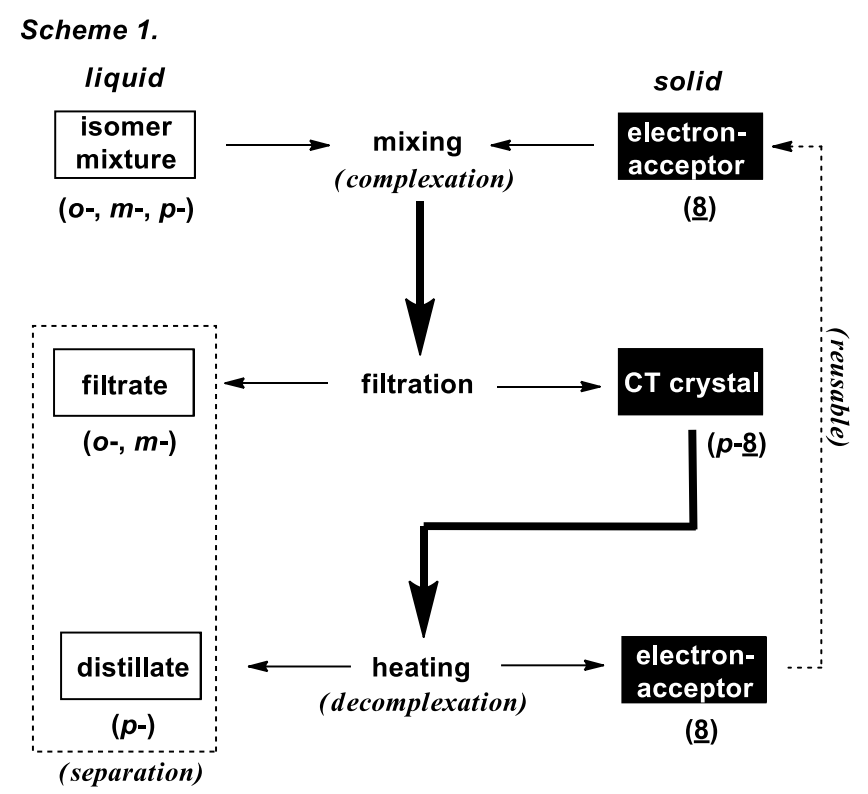

\section{Molecular design}

In both derivatives $\mathbf{1}$ and $2, \mathrm{C} \equiv \mathrm{N} \bullet \bullet \bullet \mathrm{E}-\mathrm{N}$ short-contacts were envisioned to drive molecular packing based on favorable geometric and electronic parameters. Indeed, the organization of these supramolecular synthons in the node structure are expected to lead to decreased steric hindrance in the solid state compared to the well-known chalcogenadiazole square-dimer motif ${ }^{[16]}$ (Scheme 2a,b). In addition, resonance structures reveal an enhanced electron-deficient character of the $E$ atom and an increased electron-donating character of the $\mathrm{N}$ atom of the cyano groups in these compounds, which stabilizes the overall assembly (Scheme 2c).

Furthermore, both derivatives 1 and 2 have a curved $\pi$-system and were designed to create three-dimensional cavities in the solid state. These cavities are expected to form CT crystals selectively with fused aromatics such as functionalized naphthalene compounds.

\section{Preparation and redox properties of 1 and 2}

From the corresponding naphthoquinone derivatives ${ }^{[17]}$ fused with a chalcogenadiazole ring (9 and 10, Formula), yellow crystals of $\mathbf{1}$ and $\mathbf{2}$ were obtained upon condensation reactions with malononitrile in the presence of $\mathrm{TiCl}_{4}{ }^{[18]}$ in respective yields of $74 \%$ and $89 \%$. According to DFT calculations for $\mathbf{1}$ and 2 [M06-2X/6-31G(d,p)], contribution of the polarization form (Scheme 2c) is indicated as shown by the electrostatic potentials (Scheme 2d, Figure S1). Thus, more negative Vs,min (-30.4 and $-30.1 \mathrm{kcal} \mathrm{mol}^{-1}$, respectively) is predicted for cyano $\mathrm{N}$ atom in $\mathbf{1}$ and 2 than in TCNNQ $\left(-27.5 \mathrm{kcal} \mathrm{mol}^{-1}\right)$ without a fused heterocycle. Furthermore, the more positive $\mathrm{Vs}$, max values on the chalcogen atoms in 1 and 2 ( 35.0 and $28.7 \mathrm{kcal} \mathrm{mol}^{-1}$, respectively) are calculated than in the case of the parent selenadiazole $\left(19.3 \mathrm{kcal} \mathrm{mol}^{-1}\right)$ and thiadiazole $\left(13.6 \mathrm{kcal} \mathrm{mol}^{-1}\right)$, respectively. From the more positive $\mathrm{Vs}_{\mathrm{s} \text {, max }}$, stronger $\mathrm{ChB}$ is expected in $\mathbf{1}$ than in $\mathbf{2}$, which is consistent with previous reports comparing the $\mathrm{ChB}$ in selenadiazole and thiadiazole derivatives. ${ }^{[16 a]}$

Scheme 1. Simple mixing-fltration-heating process for separation of a certain isomer from the mixture as exemplified by separation of $p$-disubstituted benzenes from the corresponding isomer mixtures by electron acceptor $\mathbf{8}$.

Scheme 2.

a)<smiles></smiles>

c)

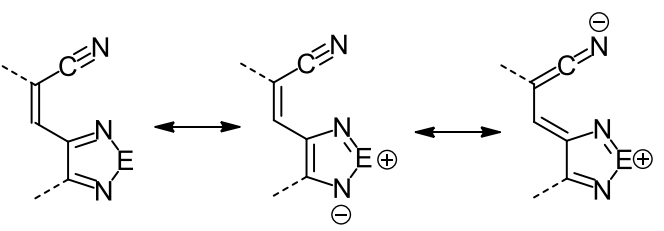

d)

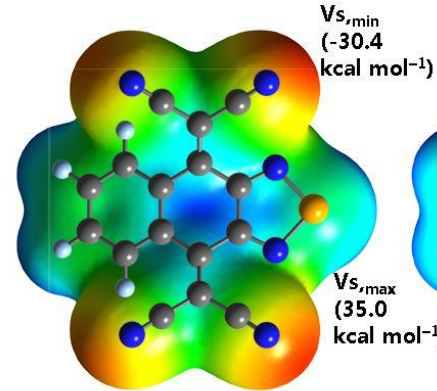

$\underline{1}$<smiles>Cc1nc2n(C)c(C)c(C)n2c1C</smiles>

b) $\ominus$ 
According to voltammetric analyses in $\mathrm{CH}_{3} \mathrm{CN}$ (Figure S2), these compounds undergo reversible two-stage one-electron reduction to give the corresponding dianions. The more negative potentials for $1\left(E_{1}-0.35 \mathrm{~V}, E_{2}-0.46 \mathrm{~V}\right.$ vs SCE in $\left.\mathrm{CH}_{3} \mathrm{CN}\right)$ than for $2(-0.22,-0.41 \mathrm{~V})$ indicates that $\mathbf{1}$ is a slightly weaker electron acceptor with a higher LUMO. For Wurster-type ${ }^{[19]}$ electron acceptors (e.g., TCNQ), aromatization of the central ring is one of the driving forces for facile one-electron reduction. The more negative $E_{1}$ for 1 than for 2 can be explained by the less aromatic nature of naphthoselenadiazole than the $S$ congener, as in the case of the weaker aromaticity of selenophene than of thiophene. When the naphthochalcogenadiazole unit accepts an electron, the less aromatic Se-congener would be reduced more easily. In fact, NLUMO of $\mathbf{1}$ or $\mathbf{2}$ has coefficients mainly on this heterocycle (Figure $\mathrm{S} 1)$, and $E_{3}$ for $1(-1.38 \mathrm{~V})$ is less negative than that for $2(-1.54 \mathrm{~V})$.

The small separation between $E_{1}$ and $E_{2}$ in $\mathbf{1}$ and $\mathbf{2}$ than in $\mathbf{3}$ $(+0.04,-0.43 \mathrm{~V})$ and $4(+0.12,-0.38 \mathrm{~V})$ without a fused benzene ring can be explained by the nonplanar structures ${ }^{[20]}$ of $\mathbf{1}$ and $\mathbf{2}$. Thus, upon two-electron transfer, a change in geometry ${ }^{[21]}$ from a folded neutral form to a twisted dianionic form (Scheme 3a) is expected, as in other benzo-fused quinodimethane derivatives. The DFT calculation also predicted a curved $\pi$-skeleton for $\mathbf{1}$ and 2 (Scheme 3b), which is characterized by the dihedral angles summarized in Table 1. The steric repulsion between the perihydrogens and cyano groups is mainly relieved by folding of the central hexagon ( $\alpha$ : $25.6^{\circ}$ for 1 and $24.7^{\circ}$ for 2 , respectively), and the twisting of exocyclic double bonds ( $\beta$ : $27.6^{\circ}$ for 1 and $26.9^{\circ}$ for 2 , respectively) is discernable due to the different steric demands of benzene and chalcogenadiazole, which are fused to each side of the TCNQ skeleton.

\section{Complexation of 1 and 2 with 2,6- and 2,7-DMN}

Upon admixing a yellow solution of $\mathbf{1}$ and a colorless solution of 2,6-DMN in $\mathrm{CH}_{2} \mathrm{Cl}_{2}$ followed by slow evaporation, $\mathrm{CT}$ crystal of 2,6-DMN•1 (1:2) was obtained as red plates. Comparisons of the IR spectra $\left(v_{\mathrm{C}=\mathrm{N}}: 2227 \mathrm{~cm}^{-1}\right.$ for 1 and $2225 \mathrm{~cm}^{-1}$ for 2,6$\mathrm{DMN} \bullet 1$, respectively) indicates that only slight charge transfer (CT) occurs from 2,6-DMN ( $E^{\mathrm{ox}}+1.46 \mathrm{~V}$ vs SCE in $\left.\mathrm{CH}_{3} \mathrm{CN}\right)$ to 1. Attempts to generate CT crystal of 1 with $2,7-\mathrm{DMN}\left(E^{\mathrm{Ox}}+1.52 \mathrm{~V}\right)$ were unfruitful, and only a mixture of uncomplexed 1 and 2,7DMN was recovered, since both compounds crystallized out separately. Thus, 1 exhibits high recognition properties toward 2,6-DMN over its 2,7-isomer. Similar behavior was observed when $\mathrm{CH}_{3} \mathrm{CN}$ or benzene was used as a solvent. In hexane, ether, or EtOH, no CT crystals were formed at all.

For the S-congener, 2,6-DMN•2 (1:2) (red plates) was obtained in a similar manner. It should be noted that 2,7-DMN•2 (1:1) was generated in the presence of a large excess amount of 2,7 DMN. After evaporation of the solvent, efflorescent red plates could be picked up as single-crystalline specimens from the polycrystalline solid of 2,7-DMN. Thus, thiadiazolo-TCNNQ 2 was proven to form CT crystals with both 2,6-and 2,7-DMNs.

To confirm that $\mathbf{1}$ and $\mathbf{2}$ show different complexation behavior during crystallization but not in solution, the association constants $\left(K_{\mathrm{CT}}\right)$ were determined for the four electron-donor-

Table 1. Dihedral angles ${ }^{a}$ showing the nonplanarity of $\mathbf{1}$ and $\mathbf{2}$

\begin{tabular}{lrll}
\hline \multicolumn{3}{c}{$\alpha{ }^{\circ}$} & $\beta /{ }^{\circ}$ \\
\hline $\begin{array}{l}\text { Selenadiazolo-TCNNQ } \\
\text { calcd. 1 }\end{array}$ & 25.6 & 27.6 \\
uncomplexed 1 $^{\mathrm{b}}$ & 31.3 & 36.1 \\
2,6-DMN•1 (1:2) & 29.2 & 32.8 \\
& & & \\
Thiadiazolo-TCNNQ & & & \\
calcd. 2 & &
\end{tabular}

aValues are averaged over the assumed Cs symmetry. The esd for the experimental values is less than $0.2^{\circ}$ unless otherwise noted ${ }^{\mathrm{b}} \mathrm{Geometries}$ were optimized by DFT method [M06-2X/6-31G(d,p)]. ctriclinic form with two independent molecules and larger esd values of $0.6^{\circ}$. ${ }^{d}$ monoclinic form.

\section{Scheme 3.}

a)

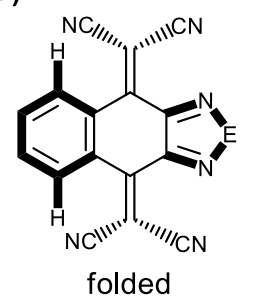<smiles>CCC(C)(C)CF</smiles>

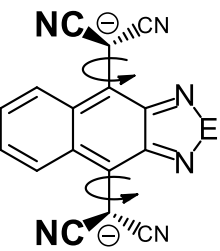

twisted b) top view

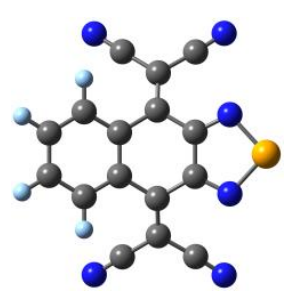

side view

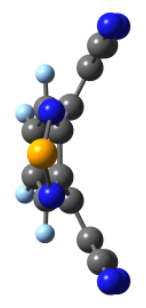<smiles>CC(C)(C)C</smiles>

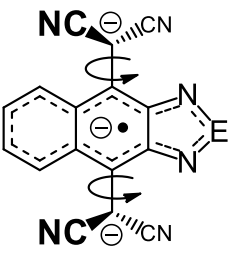

Scheme 3. a) Redox scheme for $\mathbf{1}$ and 2. The first two electron reduction processes $\left(E_{1}\right.$ and $\left.E_{2}\right)$ are accompanied by geometrical change whereas the third reduction process $\left(E_{3}\right)$ corresponds to the electron capture at the tricyclic heterocycle. b) Folded structure of 1 calculated by DFT method [M06-2X/6-31G(d,p)]. 
acceptor (EDA) complexes in $\mathrm{CH}_{2} \mathrm{Cl}_{2}$ at $0{ }^{\circ} \mathrm{C}$. The CT absorption band appears as an extended absorption tail around $500-650 \mathrm{~nm}$, which corresponds to the red color of the solutions (Figure S3). According to the Benesi-Hildebrand equation, a linear correlation was observed in all cases by assuming a 1:1 ratio. The $K_{\text {Ст }}$ values are 0.55 and $0.50 \mathrm{~mol}^{-1} \mathrm{dm}^{3}$ for 2,6-DMN - 1 and 2,7-DMN -- 1, respectively. The values for 2,6-DMN -- 2 and 2,7-DMN -- 2 (0.41 and $0.52 \mathrm{~mol}^{-1} \mathrm{dm}^{3}$, respectively) are very similar to the EDA complexes of $\mathbf{1}$. At any event, no significant recognition was observed in solution for 2,6- and 2,7DMN by 1 and 2 .

\section{Crystal structures of 1 and its CT crystal}

X-ray structural analysis (Table $\mathrm{S} 1$ ) of the light yellow crystal of uncomplexed selenadiazolo-TCNNQ 1 revealed that it had a butterfly-shaped geometry (Figure S4). Selected dihedral angles (Table 1) indicate that $\mathbf{1}$ has a curved $\pi$-plane in crystal, as predicted by the DFT calculation for an isolated gaseous molecule. The packing arrangement of uncomplexed $\mathbf{1}$ is mainly characterized by two kinds of ChB through $\mathrm{C} \equiv \mathrm{N} \bullet \bullet \bullet$ Se- $\mathrm{N}$ contacts [(i) and (ii)]. The geometries of $\mathrm{ChB}$ can be described by the distance $(D)$ of $(C \equiv) \mathrm{N} \bullet \bullet \bullet \mathrm{E}$ as well as two angles $\left(\theta_{1}:<\right.$ $\mathrm{C} \equiv \mathrm{N} \bullet \bullet \cdot \mathrm{E} ; \theta_{2}:<\mathrm{N} \bullet \bullet \mathrm{E}-\mathrm{N}$ ) (Table 2). A linear array of three atoms of $\mathrm{N} \bullet \bullet-\mathrm{E}-\mathrm{N}\left(\theta_{2} \sim 180\right)$ can warrant large stabilization of $\mathrm{ChB}$ by considering the $\sigma$-hole around the chalcogen atom. On the other hand, $C \equiv N \bullet \bullet E$ can be either linear $\left(\theta_{1} \sim 180\right)$ or perpendicular $\left(\theta_{1} \sim 90\right)$ depending on the participation of the $\mathrm{sp}_{2}$ lone pair or $2 p$ orbital of the cyano group, respectively.

By the ChB through contact (i), two molecules of $\mathbf{1}$ form a centrosymmetric dyad as shown in Scheme 2a. A similar dyad was also observed in selenadiazolo-TCNQ $3^{[13 \mathrm{c}]}$ without a fused benzene ring, and a similar association pattern is seen in the networks of bis(chalcogenadiazole) derivatives $6-8 .{ }^{[14 b]}$ The dyad is further connected by $\mathrm{ChB}$ through contact (ii) along the crystallographic $b$ axis, thus forming an infinite "dyad-ribbon" network (Figure 1). The $D$ values of (i) and (ii) are both much smaller than the sum of vdW radii of $\mathrm{N} \bullet \bullet$ Se $(3.50 \AA) ; ;^{[22]}$ by $10 \%$ and $13 \%$, respectively (Table $2 \mathrm{a}$ ). Thus, as also supported by suitable contact angles $\left(\theta_{1}\right.$ and $\left.\theta_{2}\right)$, the ChB is proven to be a strong and important director of the crystal packing of 1 . The dyad-ribbon networks are further connected to each other along the $c$ axis by weak hydrogen bonds through a $\mathrm{C}-\mathrm{H} \bullet \bullet \quad \mathrm{N}=\mathrm{C}$ contact (iii) (Table 2b), and thus a two-dimensional sheet-like structure is formed on the $b c$ plane. Since the sheets are repeated along the $a$ axis without significant interaction, the most characteristic feature is the sheet-like structure composed of dyad-ribbon networks.

Quite similar dyad-ribbon networks are formed by $\mathrm{ChB}$ through the $\mathrm{C} \equiv \mathrm{N} \bullet \bullet \bullet$ Se-N contacts [(i) and (ii)] in 2,6-DMN•1 (1:2) CT crystal (Table S1), showing that $\mathrm{ChB}$ in $\mathbf{1}$ is strong enough to be maintained upon complexation. When the $\mathrm{C}-\mathrm{H} \bullet \bullet \mathrm{N} \equiv \mathrm{C}$ hydrogen bonds are broken, however, the original sheet-like structure is separated. Between the two dyad-ribbons, an inclusion cavity for 2,6-DMN is generated (Figure 2). Close inspection indicated that three molecules of each dyad-ribbon participate to compose the cavity, which are connected by $\mathrm{C}-\mathrm{H}$ -.. $\mathrm{N} \equiv \mathrm{C}$ bonds [(iii)] at different sites from those in uncomplexed 1. Along with the two additional molecules, the dicyanomethylene group of which is located nearly in the same plane as the molecular plane of 2,6-DMN, a three-dimensional cavity is composed of 8 molecules of $\mathbf{1}$ (Figure 3 ).

Table 2. Geometrical description ${ }^{\mathrm{a}}$ for (a) $\mathrm{ChB}$ and (b) C-H $\bullet \bullet \bullet$ $\mathrm{N} \equiv \mathrm{C}$ hydrogen bond $^{\mathrm{b}}$ in $\mathbf{1}$ and $\mathbf{2}$
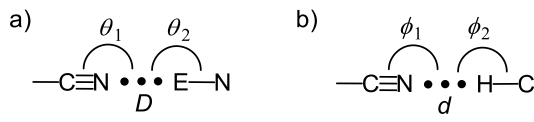

\begin{tabular}{|c|c|c|c|c|}
\hline \multicolumn{2}{|l|}{ (a) } & $D / \AA$ & $\theta_{1} /{ }^{\circ}$ & $\theta_{2} /{ }^{\circ}$ \\
\hline \multicolumn{5}{|c|}{ Selenadiazolo-TCNNQ } \\
\hline uncomplexed 1 & (i) & 3.16 & 115 & 156 \\
\hline uncomplexed 1 & (ii) & 3.04 & 159 & 177 \\
\hline 2,6-DMN•1 (1:2) & (i) & 3.27 & 121 & 154 \\
\hline 2,6-DMN•1 (1:2) & (ii) & 2.99 & 160 & 168 \\
\hline \multicolumn{5}{|l|}{ Thiadiazolo-TCNNQ } \\
\hline uncomplexed tri-2 ${ }^{\mathrm{c}}$ & (i) & 3.21 & 118 & 170 \\
\hline uncomplexed tri-2 ${ }^{\mathrm{c}}$ & (ii) & 3.17 & 124 & 156 \\
\hline \multicolumn{5}{|c|}{ uncomplexed-mono-2 $^{\mathrm{d}}$ (none) } \\
\hline 2,6-DMN•2 (1:2) & (i) & 3.38 & 121 & 151 \\
\hline 2,6-DMN•2 (1:2) & (ii) & 3.08 & 162 & 166 \\
\hline 2,7-DMN•2 (1:1) & (i) & 3.34 & 97 & 139 \\
\hline
\end{tabular}

(b)

$d / \AA \quad \phi_{1} /{ }^{\circ} \quad \phi_{2} /{ }^{\circ}$

Selenadiazolo-TCNNQ
uncomplexed 1
2,6-DMN•1 (1:2)

2,6-DMN•1 (1:2)

(iii) 2.73

129

127

Thiadiazolo-TCNNQ

uncomplexed tri-2 ${ }^{\mathrm{C}}$

uncomplexed tri-2 ${ }^{\mathrm{c}}$

uncomplexed tri-2 ${ }^{\mathrm{C}}$

uncomplexed tri-2 ${ }^{\mathrm{c}}$

uncomplexed tri-2 ${ }^{\mathrm{c}}$

(iii) 2.72

146

128

uncomplexed mono-2 ${ }^{\mathrm{d}}$

uncomplexed mono-2 ${ }^{\mathrm{d}}$

2,6-DMN•2 (1:2)

2,7-DMN•2 (1:1)

2,7-DMN•2 (1:1)

2,7-DMN•2 (1:1)

(iii) 2.69

(iv) 2.67

(v) 2.67

(vi) 2.57

(vii) 2.57

(i) 2.70

(ii) 2.53

(iii) 2.70

(ii) 2.80

(iii) 2.69

(iv) 2.60

$\begin{array}{ll}140 & 137 \\ 114 & 150 \\ 117 & 148 \\ 147 & 172 \\ 155 & 168 \\ 117 & 127 \\ 142 & 135 \\ 146 & 129 \\ 141 & 125 \\ 157 & 158 \\ 154 & 128\end{array}$

aThe esd for the distances is less than $0.1 \AA$. The esd for the angles is less than $1^{\circ}$. ${ }^{b} \mathrm{All}$ of the $\mathrm{C}-\mathrm{H}$ groups are those at the fused benzene ring of $\mathbf{1}$ and $\mathbf{2}$. ctriclinic form with two independent molecules, ${ }^{d}$ monoclinic form. 


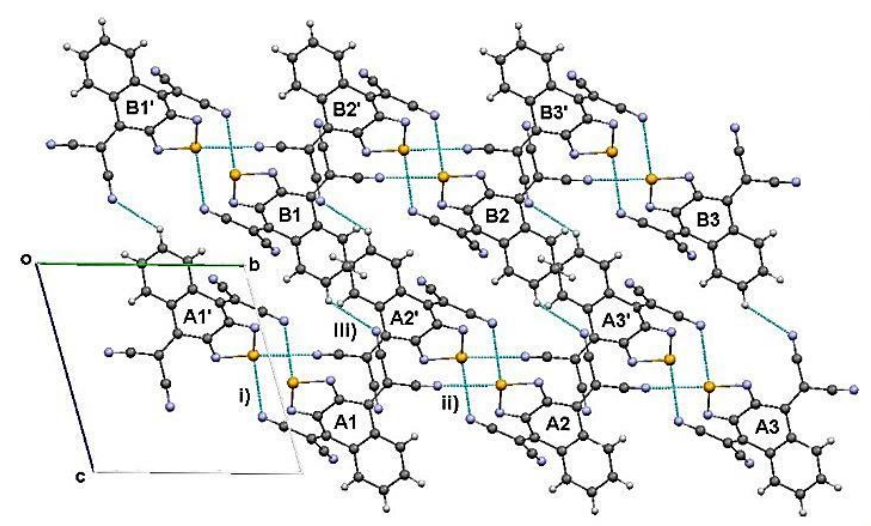

Figure 1. Sheet-like structure composed of dyad-ribbon networks in uncomplexed 1. Molecules $A 1$ and $A 1$ ' forms dyad by $\mathrm{ChB}$ through contact (i). Molecules $\mathrm{A} 1, \mathrm{~A} 2$, and $\mathrm{A} 3$ (as well as $A 1^{\prime}, A 2^{\prime}$, and $A 3^{\prime}$ ) are connected by ChB through contact (ii) to form the dyad-ribbon network. Two dyadribbons (A1-A3' and B1-B3') are connected by $\mathrm{C}-\mathrm{H} \bullet \bullet \bullet \mathrm{N} \equiv \mathrm{C}$ bonds (iii) at $\mathrm{A} 1$ and $\mathrm{B} 1$.

In the cavity, 2,6-DMN is stacked with the dicyanomethylene

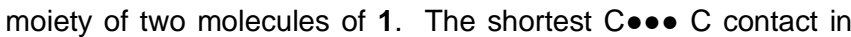
the $\pi-\pi$ overlap is $3.30 \AA$, which is less than the sum of the vdW radii $(3.40 \AA)^{[22]}$ and indicates the presence of $C T$ interaction. The recognition of 2,6-DMN over 2,7-DMN by this cavity is due to the two molecules of $\mathbf{1}$ in which the dicyanomethylene group is nearly coplanar to 2,6-DMN, thus exhibiting several short atomic contacts in the lateral direction (Figure S5), indicating that misplacement of 2,7-DMN in this cavity causes severe steric repulsion. This is why the three-dimensional cavity of 1 selectively accommodates 2,6-DMN, which is the outstanding difference from the clathrate compounds of $\mathbf{8}$ that exhibit limited selectivity for 2,6-DMN. ${ }^{[14 b]}$ Unlike 1 with a curved $\pi$-system, planar 8 forms a two-dimensional cavity (Figure S10), showing that a three-dimensional cavity is more appropriate for discriminating between 2,6- and 2,7-DMNs, which have a similar molecular shape to form a eutectic mixture. ${ }^{[23]}$

\section{Crystal structures of 2 (polymorphs) and its CT crystals}

The 2,6-DMN•2 (1:2) (Table S1, Figure S6) is isomorphous to the Se-congener, 2,6-DMN•1 (1:2). The inclusion cavity for 2,6DMN is formed by ChB through $\mathrm{C} \equiv \mathrm{N} \bullet \bullet \mathrm{S}-\mathrm{N}$ contacts [(i) and (ii)] as well as a $\mathrm{C}-\mathrm{H} \bullet \bullet \bullet \mathrm{N} \equiv \mathrm{C}$ bond [(iii)] (Table 2). While the geometrical values of (iii) are quite similar to those in 2,6DMN॰1, the ChB seems much weaker than that in the the Secongener. Thus, the $D$ value of (i) is nearly the same as the sum of vdW radii of $\mathrm{N} \bullet \bullet \mathrm{S}(3.35 \AA),{ }^{[22]}$ while that of (ii) is smaller by $8 \%$. In this way, the relative importance of $\mathrm{C}-\mathrm{H} \bullet \bullet \mathrm{N} \equiv \mathrm{C}$ is increased as a decisive factor for directing the crystal packing of $\mathbf{2}$ compared to $\mathbf{1}$.

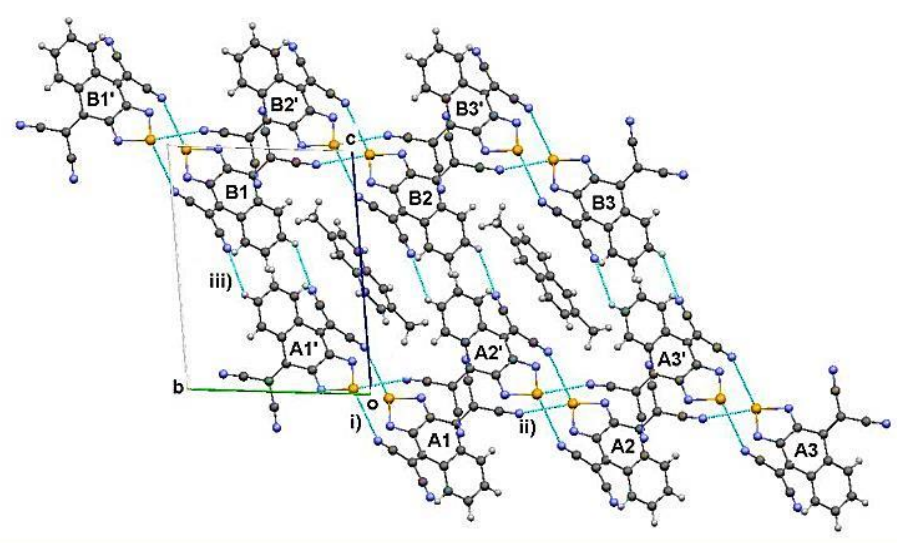

Figure 2. Cavity formation between two dyad-ribbon networks in 2,6-DMN•1 (1:2) CT crystal. Molecules A1 and $\mathrm{A} 1$ ' forms dyad by $\mathrm{ChB}$ through contact (i). Molecules $A 1, A 2$, and $A 3$ (as well as $A 1^{\prime}, A 2$ ', and $A 3^{\prime}$ ) are connected by $\mathrm{ChB}$ through contact (ii) to form the dyad-ribbon network. Two dyad-ribbons (A1-A3' and B1-B3') are connected by $\mathrm{C}-\mathrm{H} \bullet \bullet \bullet \mathrm{N} \equiv \mathrm{C}$ bonds (iii) at different sites ( $\mathrm{A} 1$ ' and $\mathrm{B} 1$ ) from those of uncomplexed 1.
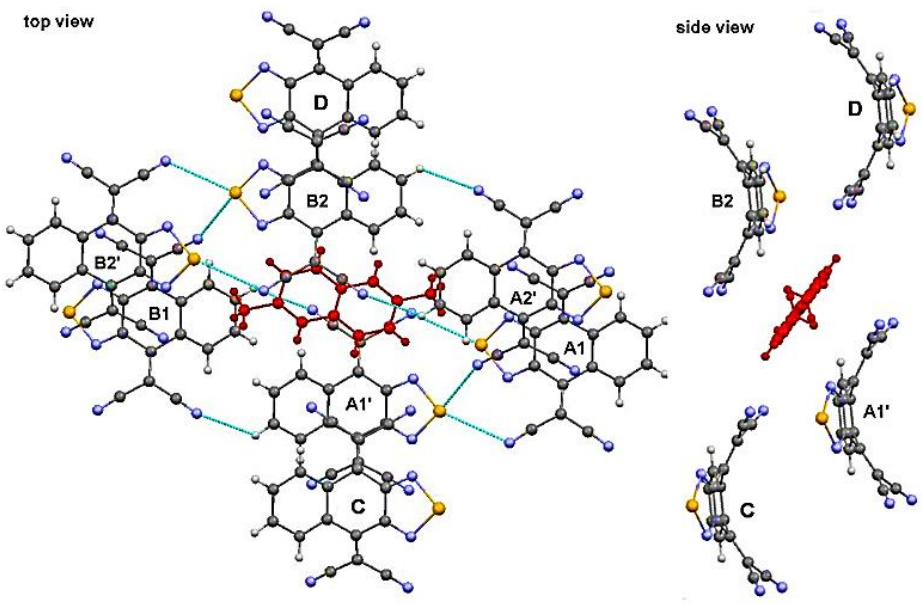

Figure 3. Inclusion of 2,6-DMN in the cavity in 2,6-DMN•1 (1:2) CT crystal. Molecules A1, A1', and A2' are part of a dyad-ribbon whereas $\mathrm{B} 1, \mathrm{~B} 2$, and $\mathrm{B} 2$ ' belong to another dyadribbon. Molecules of $\mathrm{A}^{\prime}$ ' and $\mathrm{B} 1$ as well as $\mathrm{A} 2$ ' and $\mathrm{B} 2$ are connected by $\mathrm{C}-\mathrm{H} \bullet \bullet \mathrm{N} \equiv \mathrm{C}$ bonds. 2,6-DMN was sandwitched by $\mathrm{A} 1$ ' and $\mathrm{B} 2$ through $\pi-\pi$ overlaps (shortest $\mathrm{C}$ •• C contact of $3.30 \AA)$. There are several contacts (2.93, 2.94, and $3.04 \AA$ ) between the $\mathrm{C}-\mathrm{H}$ groups of 2,6-DMN and cyano nitrogen of molecules $C$ and $D$, the dicyanomethylene group of which is located nearly in the same plane to the molecular plane of 2,6-DMN, and thus the cavity cannot accomodate 2,7-DMN. 
In fact, when we analyzed the structures of two polymorphs of uncomplexed 2 (2-tri: triclinic, $P-1, Z=4$; 2-mono: monoclinic $P 21 / \mathrm{c}, Z=4$ ), the crystal structures are mainly characterized by the networks formed by multiple $\mathrm{C}-\mathrm{H} \bullet \bullet \bullet \mathrm{N} \equiv \mathrm{C}$ bonds. For 2-tri (Table S1, Figure S7), there are two crystallographically independent molecules (mol-1 and mol-2) in the crystal. ChB through $\mathrm{C} \equiv \mathrm{N} \bullet \bullet \bullet \mathrm{S}-\mathrm{N}$ contacts [(i) and (ii)] are present, however a much larger number of $\mathrm{C}-\mathrm{H} \bullet \bullet \mathrm{N} \equiv \mathrm{C}$ bonds [(iii) - (vii)] are also noted (Table 2). No dyad was formed in the crystal. These intermolecular interactions [two ChB, (i) and (ii); five $\mathrm{C}-\mathrm{H} \bullet \bullet \bullet$ $\mathrm{N} \equiv \mathrm{C}$, (iii) - (vii)] are found only between mol-1 and mol-2. Thus, each mol- 1 is connected to seven different mol-2 whereas each mol-2 is connected to seven different mol-1 (Figure S7). The resulting three-dimensional network in 2-tri is apparently governed by $\mathrm{C}-\mathrm{H} \bullet \bullet \bullet \mathrm{N} \equiv \mathrm{C}$ bonds that overwhelm the number of ChB.

In another polymorph of 2 (2-mono) (Table S1), there is no ChB in the crystal. Instead, two kinds of $\mathrm{C}-\mathrm{H} \bullet \bullet \bullet \mathrm{N} \equiv \mathrm{C}$ contacts [(i) and (ii)] (Table 2b) connect the molecules to form a "dyadribbon" network (Figure S8). The absence of ChB is common to thiadiazolo-TCNQ $4^{[13 c]}$ without a fused benzene ring, which forms a dyad by $\mathrm{C}-\mathrm{H} \bullet \bullet \bullet \mathrm{N} \equiv \mathrm{C}$ bonds as does oxadiazolo-TCNQ 5. All of the above crystallographic results regarding 2 indicate that the $\mathrm{ChB}$ in $\mathbf{2}$ is much weaker than that in the Se-congener $\mathbf{1}$, and the $\mathrm{C}-\mathrm{H} \bullet \bullet \mathrm{N} \equiv \mathrm{C}$ bond can play an important role in determining the crystal structure of $\mathbf{2}$ and its CT crystals. Since there are four $\mathrm{C}-\mathrm{H}$ groups in $\mathbf{2}$ in contrast to only one chalcogen atom, a large variety of molecular networks would be formed based on $\mathrm{C}-\mathrm{H} \bullet \bullet \bullet \mathrm{N} \equiv \mathrm{C}$ bonds. Thus, it could be possible that 2 forms CT crystals with other DMNs (e.g., 2,7-DMN), in which crystal packing is mainly controlled by $\mathrm{C}-\mathrm{H} \bullet \bullet \bullet \mathrm{N} \equiv \mathrm{C}$ bonds.

In the crystal packing of 2,7-DMN•2 (1:1) (Table S1), we found one contact for $\mathrm{ChB}[(\mathrm{i})]$ and three contacts for $\mathrm{C}-\mathrm{H} \bullet \bullet \mathrm{N} \equiv \mathrm{C}$ bonds [(ii) - (iv)]. The geometrical features (large $D$, small $\theta_{2}$ ) of the former (Table 2a) indicate that ChB is less effective. The dyad of 2 is generated by $\mathrm{C}-\mathrm{H} \bullet \bullet \bullet \mathrm{N} \equiv \mathrm{C}$ bonds [(ii)]. The dyad is further connected by another $\mathrm{C}-\mathrm{H} \bullet \bullet \mathrm{N} \equiv \mathrm{C}$ bond [(iv)] along the crystallographic $b$ axis, to form an infinite dyad-ribbon network. Another $\mathrm{C}-\mathrm{H} \bullet \bullet \bullet \mathrm{N} \equiv \mathrm{C}$ bond [(iii)] as well as $\mathrm{ChB}$ through contact (i) connect the dyad-ribbons to form a sheet-like structure in the [201] plane (Figure 4a). Each molecule of 2 in the sheet is involved in forming an A-D-A-D mixed stack (Figure 4b), in which two independent molecular overlaps (Figure S9) are repeated along the crystallographic $c$ axis. Thus, above or below the sheet-like structure of $\mathbf{2}$, a layer is formed that contains only 2,7-DMN. Although the molecules of $\mathbf{2}$ are connected by $\mathrm{CH} \bullet \bullet N \equiv \mathrm{N}$ bonds, this CT crystal is not considered to be a clathrate compound, since no cavity is formed for 2,7-DMN.

Selenadiazolo-TCNNQ 1 renders the nearly perfect separation of 2,6-DMN from the isomer mixture, whereas thiadiazoloTCNNQ 2 does not. This quite different behavior can be rationalized in terms of the strength of ChB (Se $\bullet \bullet N$ vs $S \bullet \bullet \bullet$ $\mathrm{N}$ ), which plays an important role in molecular recognition in the solid state. a).

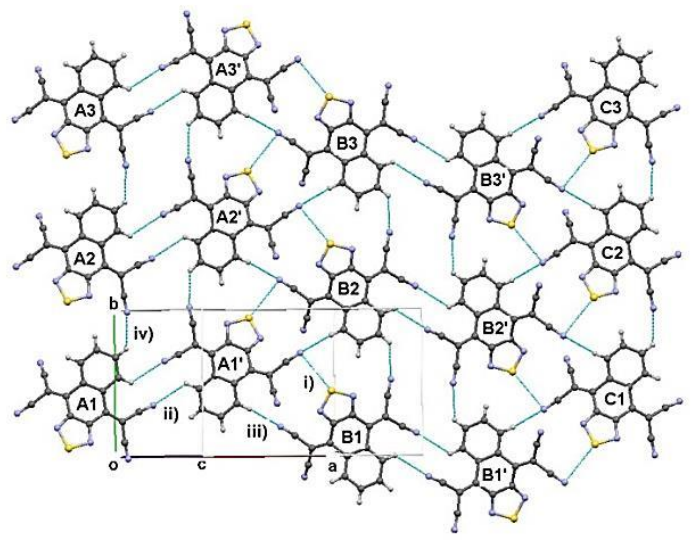

b)

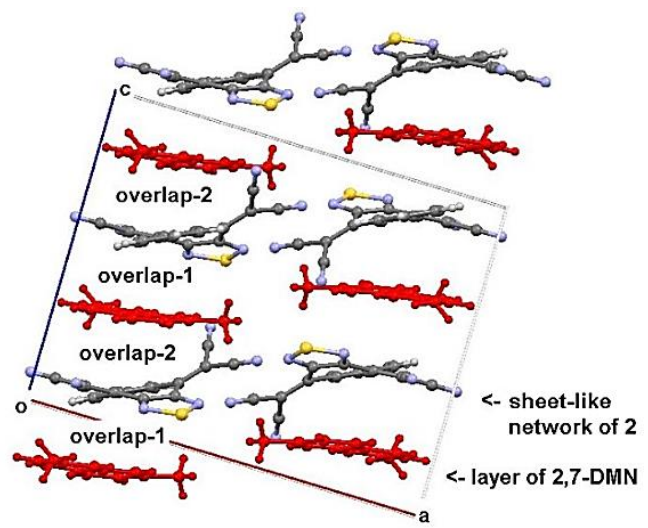

Figure 4. (a) Sheet-like structure composed of dyad-ribbon networks in 2,7-DMN•2 (1:1). Molecules A1 and A1' forms dyad by $\mathrm{C}-\mathrm{H} \bullet \bullet \bullet \mathrm{N} \equiv \mathrm{C}$ bond [(ii)]. Molecules $\mathrm{A} 1, \mathrm{~A} 2$, and $\mathrm{A} 3$ (as well as $A 1^{\prime}, A 2$ ', and $A 3^{\prime}$ ) are connected by $\mathrm{C}-\mathrm{H} \bullet \bullet \bullet \mathrm{N} \equiv \mathrm{C}$ bond [(iv)] to form the dyad-ribbon network. Two dyad-ribbons (A1-A3' and B1-B3') are connected by $\mathrm{C}-\mathrm{H} \bullet \bullet \bullet \mathrm{N} \equiv \mathrm{C}$ bond [(iii)] and weak $\mathrm{ChB}$ through contact (i). The molecule $\mathrm{C} 1$ has the coordinates of $(x+2, y, z+1)$ relateive to $A 1(x, y, z)$. (b) A-D-A-D mixed stack in 2,7-DMN•2. Sheet-like structures of 2 and layers of 2,7-DMN are repeated alternately along the $c$ axis.

\section{Separation of 2,6-DMN from a mixture by a mixing- filtration-heating process}

Finally, to demonstrate the utility of the outstanding recognition properties of 1 , selective CT crystal formation of 2,6-DMN•1 $(1: 2)$ was conducted by using a mixture obtained as a fraction at bp $250-270{ }^{\circ} \mathrm{C}$ from catalytic reforming petroleum oil. This $\mathrm{C}_{12}$ liquid contains 9.7 wt\% 2,6-DMN and 9.4 wt\% 2,7-DMN, respectively. It also contains other DMNs and several aromatic compounds (Table S2), and thus is suitable for examining the high selectivity toward 2,6-DMN.

After 1 (83 mg) was mixed with the $C_{12}$ liquid $(1.23 \mathrm{~g})$, the resulting suspension was filtered to give CT crystals $(84 \mathrm{mg})$, which were heated at $145{ }^{\circ} \mathrm{C}(14 \mathrm{mmHg})$ to give $12 \mathrm{mg}$ of 
colorless distillate accompanied by the recovery of 1 (72 $\mathrm{mg}$ ). GC analysis of the resulting distillate showed that it is $97.2 \mathrm{wt} \%$ 2,6-DMN, with slight contamination by 2,7-DMN (1.1 wt\%) and other compounds. This observation shows the high selectivity in the crystallization process between 1 and 2,6-DMN in comparison to other isomers of DMN. This outcome reflects the efficient self-sorting ${ }^{[24]}$ process between 1 and 2,6-DMN resulting from their electronic and geometrical complementarity in the solid state. As a control experiment, a similar mixing-filtrationheating process was conducted using the S-congener 2 . The resulting distillate contained not only 2,6-DMN (37.8 wt\%) but also $2,7-\mathrm{DMN}(10.5 \mathrm{wt} \%)$ as well as other DMN isomers $(39.8$ $w t \%)$. This study clearly demonstrates that the observed selfsorting process is under thermodynamic control. Indeed, the stronger ChB between molecules of $\mathbf{1}$ than between molecules of 2 undoubtedly governs the high selectivity for 2,6-DMN in this self-sorting process. This result shows the potential of crystal engineering for the purification of a polyaromatic guest from complex mixtures. Especially, purification of 2,6-DMN ${ }^{[25]}$ from raw material is an interesting approach for industrial applications since this molecule is a precursor of polyethylenenaphthalate, a promising engineering plastic. ${ }^{[26]}$

\section{Conclusions}

In this work, we have shown that a cyanovinyl-substituted chalcogenadiazole moiety is an important subunit for ChB through $\mathrm{C} \equiv \mathrm{N} \bullet \bullet \quad \mathrm{E}-\mathrm{N}$ contacts. Electron-accepting selenadiazolo-TCNNQ 1 with a curved $\pi$-system can form a dyad-ribbon network by ChB in its uncomplexed crystal, and the same motif is also found in the CT crystal with 2,6-DMN. In the latter, a three-dimensional cavity is formed between two dyadribbons, which can only accommodate 2,6-DMN and is not suitable for its regioisomers. Thus, $\mathbf{1}$ can form CT crystals only when the donor guest can be incorporated in the cavity formed by the "preorganized" dyad-ribbon network. Otherwise, 1 and the unsuitable donor crystallize out separately, as in the combination of 1 and 2,7-DMN. This is the reason why 1 can separate 2,6-DMN from the isomer mixture via a simple mixingfiltration-heating process.

On the other hand, ChB through $\mathrm{C} \equiv \mathrm{N} \bullet \bullet$ S- $\mathrm{N}$ contacts in thiadiazolo-TCNNQ 2 is weaker, and thus cannot always be the determinaning factor for crystal packing. Actually, one of the polymorphs of uncomplexed 2 (2-tri, triclinic form) has a crystal structure with two $\mathrm{ChB}$, but the molecules are further connected through five $\mathrm{C}-\mathrm{H} \bullet \bullet \mathrm{N} \equiv \mathrm{C}$ bonds. In another polymorph (2mono, monoclinic form), no $\mathrm{ChB}$ is present and crystal packing is characterized by $\mathrm{C}-\mathrm{H} \bullet \bullet \bullet \mathrm{N} \equiv \mathrm{C}$ bonds. Although 2,6-DMN•2 $(1: 2)$ is crystallized isomorphously to the Se-congener [2,6DMN•1 (1:2)] to select 2,6-DMN among other isomers, 2 can form other packing arrangements by $\mathrm{C}-\mathrm{H} \bullet \bullet \mathrm{N} \equiv \mathrm{C}$ bonds so that 2 forms CT complexes with other isomers as in the case of 2,7-DMN•2 (1:1). Accordingly, the ability of 2 to recognize DMN isomers is low due to the "induced fit"-type complexation via C-H $\bullet \bullet \bullet \mathrm{N} \equiv \mathrm{C}$ bonds.

For the future design of clathrate-host molecules for molecular recognition, a "preorganized" supramolecular synthon formed by ChB would make a good molecular design concept, and the use of $\mathrm{Se}$ (or Te) would be more promising by strengthening network formation without being perturbed by other interactions such as $\mathrm{C}-\mathrm{H} \bullet \bullet \times \mathrm{X}$ bonds or halogen bonds. ${ }^{[27]}$ While the additional use of other weak interactions would lead to more sophisticated recognition, care should be taken so that some other interaction never overwhelms ChB.

\section{Acknowledgements}

We thank JSPS Kakenhi (Nos. 19K15528, 20H02719, 20K21184). Financial supports from The Hattori Hokokai Foundation, Toyota Riken Scholar and The NOVARTIS Foundation (Japan) are gratefully acknowledged. This work is supported by "Five-star Alliance" in "NJRC Mater. Dev." MEXT.

Keywords: Crystal engineering Selenium• Cocrystallization • Isomer separation• Self-sorting

[1] A. Bauz, T. J. Mooibroek, A. Frontera, ChemPhysChem 2015, 16, 2496-2517.

[2] D. J. Pascoe, K. B. Ling, S. L. Cockroft, J. Am. Chem. Soc. 2017, 139, 15160-15167.

[3] H. A. Bent, Chem. Rev. 1968, 68, 587-648.

[4] For recent reviews: a) J. Y. C. Lim, P. D. Beer, Chem 2018, 4, 731783; b) L. Vogel, P. Wonner, S. M. Huber, Angew. Chem. Int. Ed. 2019, 58, 1880-1891; c) N. Biot, D. Bonifazi, Coord. Chem. Rev. 2020, 413, 213243.

[5] W. Wang, B. Ji, Y. Zhang, J. Phys. Chem. A 2009, 113, 8132-8135.

[6] A. Bauzá, D. Quiñonero, P. M. Deyà, A. Frontera, CrystEngComm 2013, 15, 3137-3144

[7] L.-J. Riwar, N. Trapp, K. Root, R. Zenobi, F. Diederich, Angew. Chem. Int. Ed. 2018, 57, $17259-17264$.

[8] a) K. T. Mahmudov, M. N. Kopylovich, M. F. C. Guedes da Silva and Armando J. L. Pombeiro, Dalton Trans. 2017, 46,10121-10138; b) R. Weiss, E. Aubert, P. Peluso, S. Cossu, P. Pale, V. Mamane, Molecules 2019, 24, 4484; J. Bamberger, F. Ostler, O. García Mancheño, ChemCatChem 2019, 11, 5198-5211.

[9] a) H.-T. Huynh, O. Jeannin, M. Fourmigué, Chem. Commun. 2017, 53, 8467-8469; f) Y. Zhang, W. Wang, Crystals 2018, 8, 163; b) P. Scilabra, G. Terraneo, G. Resnati, Acc. Chem. Res. 2019, 52, 1313-1324

[10] a) G. R. Desiraju, Angew. Chem. Int. Ed. 1995, 34, 2311-2327; b) A. Nangia, G. R. Desiraju, Acta Cryst. 1998, A54, $934-944$; c) P. Metrangolo, H. Neukirch, T. Pilati, G. Resnati, Acc. Chem. Res. 2005 38, 386-395; d) G. R. Desiraju, J. Am. Chem. Soc. 2013, 135, 9952 9967.

[11] . J. P. Dunitz, Pure Appl. Chem. 1991, 63, 177-185

[12] a) T. M. Klapötke, B. Krumm, J. C. Gálvez-Ruiz, H. Nöth, I. Schwab, Eur. J. Inorg. Chem. 2004, 4764-4769; b) T. M. Klapötke, B. Krumm, M. Scherr, Inorg. Chem. 2008, 47, 7025-7028 ; c) Y. Berrueta Martínez, L. S. Rodríguez Pirani, M. F. Erben, R. Boese, C. G. Reuter, Y. V. Vishnevskiy, N. W. Mitzel, C. O. Della Védova, ChemPhysChem 2016, 17, 1463-1467; d) Y. Berrueta Martínez, L. S. Rodríguez Pirani, M. F. 
Erben, R. Boese, C. G. Reuter, Y. V. Vishnevskiy, N. W. Mitzel, C. O. Della Védova, J. Mol. Struct. 2017, 1132, 175-180; e) V. Previtali, G. Sánchez-Sanz, C. Trujillo, ChemPhysChem 2019, 20, 3186-3194.

[13] a) Y. Yamashita, T. Suzuki, T. Mukai, G. Saito, J. Chem. Soc., Chem. Commun. 1985, 1044-1045; b) T. Suzuki, Y. Yamashita, C. Kabuto, T. Miyashi, J. Chem. Soc., Chem. Commun. 1989, 1102-1103; c) T. Suzuki, Y. Yamashita, T. Fukushima, T. Miyashi, Mol. Cry. Liq. Cry. 1997, 296, 165-180.

[14] a) T. Suzuki, C. Kabuto, Y. Yamashita, T. Mukai, T. Miyashi, G. Saito, Bull. Chem. Soc. Jpn. 1988, 61, 483-493; b) T. Suzuki, H. Fujii, Y. Yamashita, C. Kabuto, S. Tanaka, M. Harasawa, T. Mukai, T. Miyashi, J. Am. Chem. Soc. 1992, 114, 3034-3043; c) T. Suzuki, T. Fukushima, Y. Yamashita, T. Miyashi, J. Am. Chem. Soc. 1994, 116, 2793-2803.

[15] a) Some parts of preparation and properties of 1 and 2 have been published as preliminary communications (ref. 13a, 15b); b) T. Suzuki, C. Kabuto, Y. Yamashita, T. Mukai, Chem. Lett. 1987, 16, 1129-1132.

[16] a) S. Tsuzuki, N. Sato, J. Phys. Chem. B 2013, 117, 6849-6855; b) A. V. Lonchakov, O. A. Raktin, N. P. Gristsan, A. V. Zibarev, Molecules 2013, 18, 9850-9900; c) S. Langis-Barsetti, T. Maris, J. d. Wuest, J. Org. Chem. 2017, 82, 5034-5045; d) M. R. Ams, N. Trapp, A. Schwab, J. V. Milić, F. Diederich, Chem. Eur. J. 2019, 25, 323-333.

[17] a) R. Neeff, O. Bayer, Chem. Ber. 1957, 90, 1137-1145; b) R. Neidlein, D. Tran-Viet, A. Gieren, M. Kokkinidis, R. Wilckens, H. Geserich, W. Rüppel, Chem. Ber. 1982, 115, 2898-2904.

[18] a) W. Lehnert, Tetrahedron Lett. 1970, 11, 4723-4724; b) A. Aumüller, S. Hünig, Liebigs Ann. Chem.1984, 618-621.

[19] K. Deuchert, S. Hünig, Angew. Chem. Int. Ed. 1978, 17, 875-958.

[20] a) U. Schubert, S. Hünig, A. Aumüller, Liebigs Ann. Chem. 1985, 1216-1222.; b) N. Martin, M. Hanack, J. Chem. Soc., Chem. Commun. 1988, 1522-1524: c) R. Gómez, C. Seoane, J. L. Segura, Chem. Soc Rev. 2007, 36, 1305-1322; d) F. Bureš, W. Bernd Schweizer, C Boudon, J. -P. Gisselbrecht, M. Gross, F. Diederich, Eur. J. Org. Chem. 2008, 994-1004

[21] a) Y. Ishigaki, K. Sugawara, M. Yoshida, M. Kato, T. Suzuki, Bull. Chem. Soc. Jpn. 2019, 92, 1211-1217; b) Y. Ishigaki, Y. Hayashi. Y. Hayashi, T. Suzuki, J. Am. Chem. Soc. 2019, 141, 18293-18300.

[22] L. Pauling, "The nature of the chemical bond and the structure of molecules and crystals: An introduction to modern structural chemistry," 3rd ed Cornell University Press; Ithaka, NY, 1960.

[23] J. A. Hodge, "Advances in Chemistry". 102 (Molecular Sieve ZeolitesII) , Chapter 59, pp. 238-246. ACS Publications, Washington, DC,1971,

[24] a) J.-M. Lehn, Chem. Eur. J. 1999, 5, 2455-2463; b) A. Wu, L. Isaacs, J. Am. Chem. Soc. 2003, 125, 4831-4835; c) P. Mukhopadhyay, A. Wu, L. Isaacs, J. Org. Chem. 2004, 69, 6157-6164; d) S. Liu, C. Ruspic, P. Mukhopadhyay, S. Chakrabarti, P. Y. Zavalij, L. Isaacs, J. Am. Chem. Soc. 2005, 127, 15959-15967; e) P. Mukhopadhyay, P. Y. Zavalij, L. Isaacs, J. Am. Chem. Soc. 2006, 128, 14093-14102.

[25] a) S. J. Kim, Appl. Chem .Eng. 2018, 29, 799-804; b) H. Ban, Y. Cheng, L. Wang, X. Li, X. Zhou, X. Zhang, Chem. Eng. Technol. 2019, 42 1188-1198.

[26] a) T. Someya, T. Sekitani, S. Iba, Y. Kato, H. Kawaguchi, T. Sakurai, Proc. Nat. Acad. Sci. 2004, 101, 9966-9970; b) Res. Chem. Intermed. 2020, 46, 2403-2416.

[27] a) D. Bulfield, S. M. Huber, Chem. Eur. J. 2016, 22, 14434-14450; b) H. Wang, H. K. Bisoyi, A.. Urbas, T. J. Bunning, Q. Li, Chem. Eur. J. 2019 25, 1369-1378; c) P. Scilabra, G. Terraneo, G. Resnati, Acc. Chem Res. 2019, 52, 1313-1324; d) P. R. Varadwaj, A. Varadwaj, H. M. Marques, Inorganics 2019, 7, 40. 
Entry for the Table of Contents (Please choose one layout)

Layout 1:

\section{FULL PAPER}

Chalcogen makes the change:

Highly selective cocrystallization with 2,6-dimethylnaphthalene (2,6-DMN) allows the title selenadiazole-based electron acceptor to separate 2,6 DMN from the isomer mixture by an effective Se $\bullet \bullet \bullet N$ chalcogen bond whereas the sulfur congener shows only low selectivity due to the competing $\mathrm{C}-\mathrm{H} \bullet \bullet \bullet \mathrm{N}$ hydrogen bond, which overwhelms the $\mathrm{S} \bullet \bullet \bullet$ $\mathrm{N}$ bond.

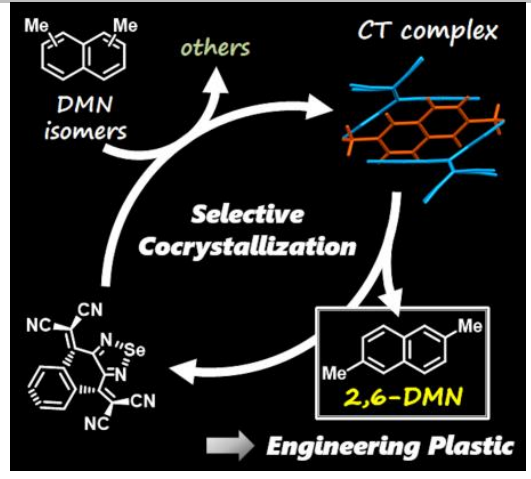

Yusuke Ishigaki, Kota Asai, Henri-Pierre Jacquot de Rouville, Takuya Shimajiri, Valérie Heitz, Hiroshi Shinomiya-Fujii, and Takanori Suzuki

Page No. - Page No.

Molecular Recognition by Chalcogen Bond: Selective Charge-transfer Crystal Formation of Dimethylnaphthalene with 